\title{
EFFECTS OF AUTOMOTIVE INTERIOR LIGHTING ON DRIVER VISION
}

\author{
Joel M. DeVonshire \\ MichaEL J. FLANNAGAN
}

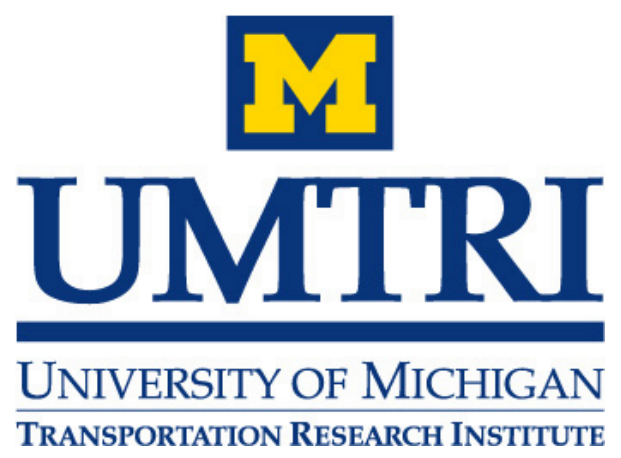




\section{EFFECTS OF AUTOMOTIVE INTERIOR LIGHTING ON DRIVER VISION}

Joel M. Devonshire

Michael J. Flannagan

The University of Michigan Transportation Research Institute

Ann Arbor, Michigan 48109-2150

U.S.A.

Report No. UMTRI-2007-1

March 2007 
Technical Report Documentation Page

\begin{tabular}{|c|c|}
\hline $\begin{array}{l}\text { 1. Report No. } \\
\text { UMTRI-2007-1 }\end{array}$ & 3. Recipient's Catalog No. \\
\hline \multirow[t]{2}{*}{$\begin{array}{l}\text { 4. Title and Subtitle } \\
\text { Effect of Automotive Interior Lighting on Driver Vision }\end{array}$} & $\begin{array}{l}\text { 5. Report Date } \\
\text { March } 2007\end{array}$ \\
\hline & $\begin{array}{l}\text { 6. Performing Organization Code } \\
302753\end{array}$ \\
\hline $\begin{array}{l}\text { 7. Author(s) } \\
\text { Devonshire, J.M. \& Flannagan, M.J. }\end{array}$ & $\begin{array}{l}\text { 8. Performing Organization Report No. } \\
\text { UMTRI-2007-1 }\end{array}$ \\
\hline \multirow{2}{*}{$\begin{array}{l}\text { 9. Performing Organization Name and Address } \\
\text { The University of Michigan } \\
\text { Transportation Research Institute } \\
\text { 2901 Baxter Road } \\
\text { Ann Arbor, Michigan 48109-2150 U.S.A. }\end{array}$} & 10. Work Unit no. (TRAIS) \\
\hline & 11. Contract or Grant No. \\
\hline \multirow{2}{*}{$\begin{array}{l}\text { 12. Sponsoring Agency Name and Address } \\
\text { The University of Michigan } \\
\text { Industry Affiliation Program for } \\
\text { Human Factors in Transportation Safety }\end{array}$} & 13. Type of Report and Period Covered \\
\hline & 14. Sponsoring Agency Code \\
\hline
\end{tabular}

The Affiliation Program currently includes Alps Automotive/Alpine Electronics, Autoliv, Avery Dennison, Bendix, BMW, Bosch, Com-Corp Industries, DaimlerChrysler, Decoma Autosystems, Denso, Federal-Mogul, Ford, GE, General Motors, Gentex, Grote Industries, Hella, Honda, Ichikoh Industries, Koito Manufacturing, Lang-Mekra North America, Magna Donnelly, Muth, Nissan, North American Lighting, Northrop Grumman, OSRAM Sylvania, Philips Lighting, Renault, Sisecam, SL Corporation, Stanley Electric, Toyota Technical Center USA, Truck-Lite, Valeo, Visteon/ACH, and 3M Personal Safety Products. Information about the Affiliation Program is available at: http://www.umich.edu/ industry

16. Abstract

There has been growing interest in vehicle interior lighting for both functional and esthetic purposes. Although a large body of research has developed over many years on nighttime driver vision and vehicle exterior lighting, there has traditionally been little research attention to interior lighting. This report includes a brief review of some of the research that has been done, and presents the results of a nighttime field study that was performed to contribute to the understanding of how vehicle interior lighting affects some basic aspects of driver vision. Participants in the study were asked to perform two tasks while seated in a stationary experimental car on a closed test road at night: (1) detecting pedestrians on the road ahead, and (2) rating the subjective brightness of a reflected veiling light on the windshield. The veiling light was varied in both luminance and color. The results indicated that pedestrian detection was closely related to photopic photometric measures, suggesting the pedestrian task was influenced primarily by cone photoreceptors, while the rating of subjective brightness appeared to show an influence of rod photoreceptors. These results have implications for how the photometry of vehicle interior lighting should be performed in order to give the best correlation with driver visual performance. Future research should further quantify the effects observed here and investigate changes in retinal adaptation associated with automotive interior lighting.

\begin{tabular}{|l|l} 
17. Key Words & 18. Distribution Statement
\end{tabular}

vehicle lighting, interior lighting, day vision, night vision, photometry, Unlimited photopic, scotopic, mesopic, pedestrian visibility

\begin{tabular}{|l|l|c|l|}
\hline $\begin{array}{l}\text { 19. Security Classification (of this report) } \\
\text { None }\end{array}$ & $\begin{array}{l}\text { 20. Security Classification (of this page) } \\
\text { None }\end{array}$ & $\begin{array}{c}\text { 21. No. of Pages } \\
23\end{array}$ & 22. Price
\end{tabular}




\section{ACKNOWLEDGEMENTS}

Appreciation is extended to the members of the University of Michigan Industry Affiliation Program for Human Factors in Transportation Safety for support of this research. The current members of the Program are:

$\begin{array}{ll}\text { Alps Automotive/Alpine Electronics } & \text { Koito Manufacturing } \\ \text { Autoliv } & \text { Lang-Mekra North America } \\ \text { Avery Dennison } & \text { Magna Donnelly } \\ \text { Bendix } & \text { Muth } \\ \text { BMW } & \text { Nissan } \\ \text { Bosch } & \text { North American Lighting } \\ \text { Com-Corp Industries } & \text { Northrop Grumman } \\ \text { DaimlerChrysler } & \text { OSRAM Sylvania } \\ \text { Decoma Autosystems } & \text { Philips Lighting } \\ \text { Denso } & \text { Renault } \\ \text { Federal-Mogul } & \text { Sisecam } \\ \text { Ford } & \text { SL Corporation } \\ \text { GE } & \text { Stanley Electric } \\ \text { General Motors } & \text { Toyota Technical Center, USA } \\ \text { Gentex } & \text { Truck-Lite } \\ \text { Grote Industries } & \text { Valeo } \\ \text { Hella } & \text { Visteon/ACH } \\ \text { Honda } & 3 \text { M Personal Safety Products } \\ \text { Ichikoh Industries } & \end{array}$




\section{CONTENTS}

ACKNOWLEDGEMENTS .............................................................................. ii

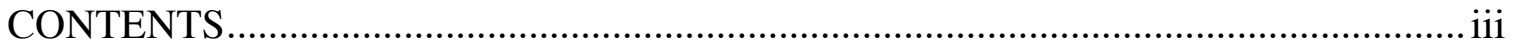

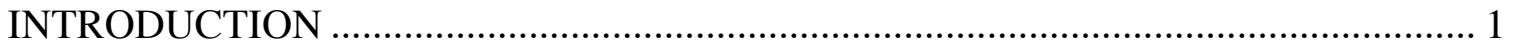

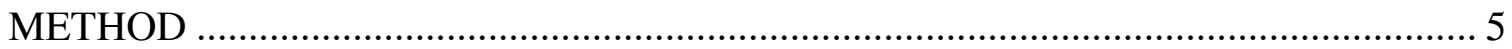

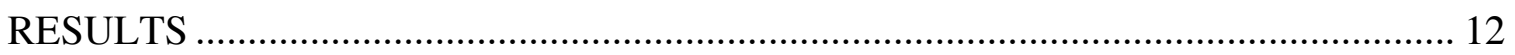

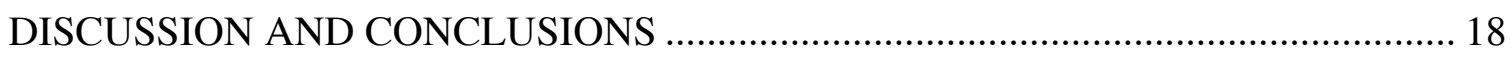

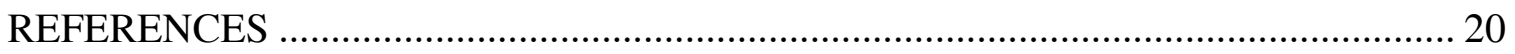




\section{INTRODUCTION}

Over many decades, the majority of the research on automotive lighting and driver vision has been about exterior vehicle lamps (e.g., headlamps, brake lights, turn signals, etc.) and fixed roadway lighting. Comparatively little research has been done on interior lighting of the vehicle and the effects interior light sources may have on the driver's ability to see outside of the vehicle. With the introduction of new lighting technologies such as organic light emitting diodes (OLEDs) and "light pipes," options for implementing interior lighting systems have recently become more cost-effective and flexible, both functionally and esthetically. In addition, as navigation and entertainment systems have become more common, there have been an increasing number of light sources in vehicle cabins. While a substantial amount of research has been conducted related to the visual aspects of in-vehicle displays, the focus has generally been on legibility and subjective preference for the brightness and/or color of the displays themselves. Until more is known about the effects of automotive interior lighting on drivers' visual performance, alertness, and distraction, it is difficult to assess its safety potential. For example, while it might be argued that more light inside the vehicle could provide benefits such as increased driver alertness and less required time to locate and operate interior controls, these potential benefits could be offset by degraded vision outside of the vehicle or by a greater degree of visual distraction.

In the next several years, there will be an increase in knowledge about the effects of interior lighting, from both practical experience and formal research. In this report, we review previous research on interior lighting and present new data from a field study designed to better understand how the luminance and color of interior lighting affect some basic aspects of driver vision. The color of interior lighting is particularly of interest for esthetic reasons, and it raises important issues about photometry-about how light should be defined and measured for this application area.

\section{Trends in interior lighting}

Until fairly recently, automotive interior lighting has been limited to what could broadly be called "functional" uses. Examples of functional lighting include dome and map lights located on the ceiling of the vehicle, backlit instrument panel displays and 
controls, and door panel lamps that turn on when the doors are open. Functional lighting is generally used when the vehicle is stationary, and is commonly used to assist in activities such as entering or exiting the vehicle at night, orienting oneself before starting the vehicle, and consulting printed maps.

Within the last five to ten years, there has been a growing interest in developing interior lighting systems with more esthetic or psychological appeal. Broadly termed "ambient lighting," these systems dimly accentuate aspects of the interior environment, including doors, the center console, foot wells, and so forth. In these systems, the light source is often not visible to the driver. Rather, most or all of the visible light is reflected from interior surfaces. Ambient lighting systems typically remain on while driving, and are designed to enable the driver to more easily see and manipulate interior controls, and to enhance the driver's mood, alertness, and comfort. Ambient lighting has become a popular option for many luxury vehicles, in part because of improvements in the technology to implement it (e.g., OLEDs, fiber optics, electroluminescent films).

\section{Interior lighting and vision: Past research}

While functional and ambient automotive interior lighting systems have evolved over time, they have not received a great deal of attention from an automotive safety standpoint. A few studies have examined typical interior light levels while driving at night (e.g., Grimm, 2003; Kerst \& Bos, 1988; Navvab, 1991), or subjective preferences for the brightness and color of interior displays and controls (e.g., Grimm, 2003; Imbeau, 1987; Langolf, Mourant, \& Fisher, 1974; Serafin \& Green, 1990).

One study compared an alternative map light, built into the rearview mirror, to both standard interior lighting and no interior lighting in terms of how they affected the threshold luminance of a stationary disk target (Olson, 1985). The target was viewed through the windshield and rear window of three different vehicles, each of which had its standard interior lighting replaced with the new map light. As the subjects sat in the driver's seat of each vehicle, an experimenter adjusted the luminance of the target for each condition and recorded the luminance at which the target was detected. The results showed that visibility was best when no lights were on in the vehicle, and worst with the standard interior lighting. When the luminance values were translated into approximations of visibility distance, it was calculated that turning on standard map 
lights reduced forward visibility by roughly 10 to $20 \%$. The alternative map light was associated with better visibility than standard lighting, and in some cases was equivalent to the no-light condition. These relationships held for both forward-looking and rearlooking scenarios.

In what is probably the major research effort in this area, Grimm (2003) used static laboratory and dynamic driving tests of various interior lighting configurations, asking subjects to give subjective ratings of visual comfort and examining objective tests of threshold luminance detection. Although this study is too extensive to thoroughly review here, it is worth noting that it is distinguished by the fact that it provides a systematic investigation of newer ambient lighting concepts. Among its conclusions is that, while ambient interior lighting systems have the potential to decrease comfort and visibility, their potential effects are largely dependent on factors such as the location, color, intensity, and size of the light sources.

\section{Background considerations}

It has probably been assumed that drivers will self-regulate levels of interior light, and will turn a light source off if it causes a subjective disturbance. Thus, functional interior lighting systems that can be used while driving are typically adjustable by the driver such that they can be made barely visible or turned off. Current trends, however, include placing more light inside the vehicle, whether from ambient lighting systems, navigation systems, or other vehicle telematics systems. Some of these systems are portable and not designed for exclusively automotive use.

Two effects of automotive interior lighting are especially relevant to driver visual performance: possible changes in the driver's visual adaptation, and veiling stimulation caused by scattered or reflected light on the windshield or in the eye. These effects may exist for either functional or ambient interior lighting.

The driver's state of visual adaptation during night driving is a relatively wellresearched topic. Driving at night typically results in a range of mesopic adaptation levels that may continually fluctuate because of the headlamp-illuminated areas of the roadway, oncoming glare sources, and transient changes in overhead lighting and other roadway light sources. Less is known, however, about how glances at relatively highluminance stimuli within the vehicle might affect the state of visual adaptation. For 
example, as adaptation changes from low mesopic to high mesopic levels, might there be changes in rod/cone sensitivity that could affect the detection of pedestrians or other obstacles in the road?

Similarly, the topic of veiling glare has received a good deal of research attention, but few studies have investigated the role of interior lighting. Do current interior lighting systems pose any risks for disability or discomfort glare? How do the factors of color, viewing angle, and luminance on the windshield affect vision? What is the relationship between drivers' subjective impressions and objective visual performance when light is introduced inside the vehicle? The present study was designed as a preliminary investigation into some of these latter questions. 


\section{METHOD}

\section{Participants}

There were 8 paid participants, balanced by age and gender. Four were in a younger age group (between 18 and 23 years old with a mean age of 21.5 years) and four were in an older age group (between 60 and 70 years old with a mean age of 64.0 years). The participants were recruited from a list of volunteers maintained at UMTRI. All participants were licensed drivers with normal color vision and visual acuity that fell within legal driving limits. During their pre-test instruction, participants were told that the vehicle's interior lighting would be changed from trial to trial, but they did not know exactly how or why these manipulations were taking place.

\section{Task}

In the first part of the experiment, participants were asked to detect a pedestrian walking along a road, both toward and away from them. Instructions were read to each participant at the beginning of the experiment. The wording was as follows:

During this experiment, we would like you to sit in the driver's seat of this car and look out the front window. Your job will be to detect a pedestrian who will walk toward you, and then away, on the road ahead. On each of a series of trials, the pedestrian will start from far enough down the road that you will not be able to see her with the light from the headlamps. She will then walk toward us at a steady pace. Please indicate - by pressing the radio talk button once quicklywhen you can just see her. She will continue walking toward us, stop, turn around, and walk away. As she walks away, please indicate - also by quickly pressing the radio talk button-when she has just disappeared from your sight.

Sometimes the pedestrian will be on the right side of the road, and sometimes she will be in the middle of the road. The lighting in the car will be changed from trial to trial, and this may affect your ability to see the pedestrian. In all cases, please try to indicate the furthest point at which you can just see the pedestrian.

The second part of the experiment consisted of a magnitude estimation task in which the participants were asked to give ratings of the perceived brightness of a reflected image on the windshield. The instructions read to the participants follow:

In this part of the experiment, I would like you to make numerical ratings of the brightness of the rectangular field of light that you see reflected in the windshield. Please try to rate the brightness of the reflected light alone, although you will always be seeing it against the light of the headlamps on the road scene. 
Here is a standard to use in assigning numbers [the white, $0.13 \mathrm{~cd} / \mathrm{m}^{2}$ stimulus]. I would like you to consider this brightness equal to 100 . In the series of trials that I am about to present, please try to make all your judgments proportional to this one. That is, if a certain stimulus seems half as bright as this one, call it 50. If it seems twice as bright, call it 200. You can use any positive numbers, including decimals or fractions if you want to.

\section{Test site and materials}

The experiment was conducted on the entrance drive to a golf course in Ann Arbor, Michigan, which was closed at night. The road was straight and relatively flat, and was $4.8 \mathrm{~m}$ (15.6 feet) wide (see Figure 1). All sessions were conducted at night, with dry pavement. Participants sat in the driver's seat of a stationary 2003 midsize sedan with its tungsten-halogen low-beam headlamps on. The vehicle was parked along the right side of the road, as shown in Figure 1. Other than the vehicle's headlamps, there were no light sources (vehicular or fixed) present. The vehicle's windshield and headlamps were cleaned at the beginning of each evening. Figure 2 shows the road from the driver's perspective.

The stimuli were presented using a 43.2-centimeter (17-inch) flat-panel LCD monitor that was placed on the vehicle's dashboard, such that a rectangular image of the monitor was reflected in the windshield in front of the participant. The monitor was connected to a laptop computer, which was used to present uniform color slides. Via software controls, three slides were created of approximately equal photopic luminance $\left(0.5 \mathrm{~cd} / \mathrm{m}^{2}\right.$ when reflected on the windshield and viewed from the driver's seat) but different color (white, blue, and red). Three neutral density filters were also used during the experiment to reduce the luminance of these slides proportionally. Each filter nominally reduced light transmittance to $25 \%$ of the level above it. In other words, the five levels of reflected luminance were $0.5 \mathrm{~cd} / \mathrm{m}^{2}$ (unfiltered), $0.13 \mathrm{~cd} / \mathrm{m}^{2}$ (filter density 0.6 ), $0.0 .31 \mathrm{~cd} / \mathrm{m}^{2}$ (filter density 1.2 ), $0.0078 \mathrm{~cd} / \mathrm{m}^{2}$ (filter density 1.8 ), and $0.0 \mathrm{~cd} / \mathrm{m}^{2}$ (monitor turned off). The filters were applied using three separate frames that could be quickly applied to and removed from the monitor. Figure 3 shows an example of what the experimental setup looked like from the participant's perspective.

Two experimenters were involved in data collection. One experimenter sat in the passenger seat of the vehicle and changed the reflected stimulus between trials. The second experimenter acted as the pedestrian, and communicated with the first 
experimenter via a two-way radio. The pedestrian wore a sweatshirt and sweatpants that were dark gray $(8 \%$ reflectance for tungsten-halogen headlamps measured in photopic units), and black shoes.

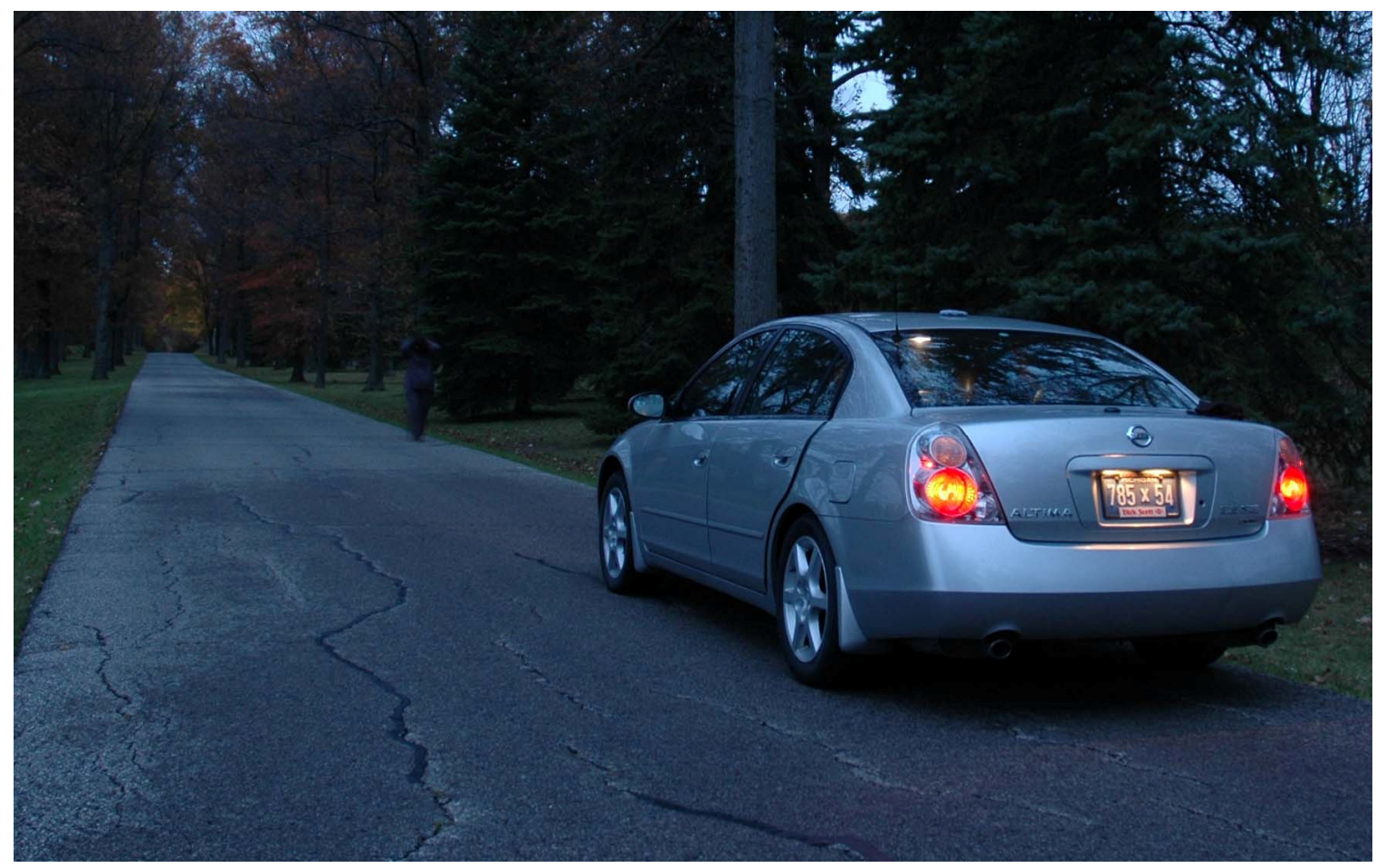

Figure 1. Stationary test vehicle and pedestrian at the site, daytime photo for illustration. 


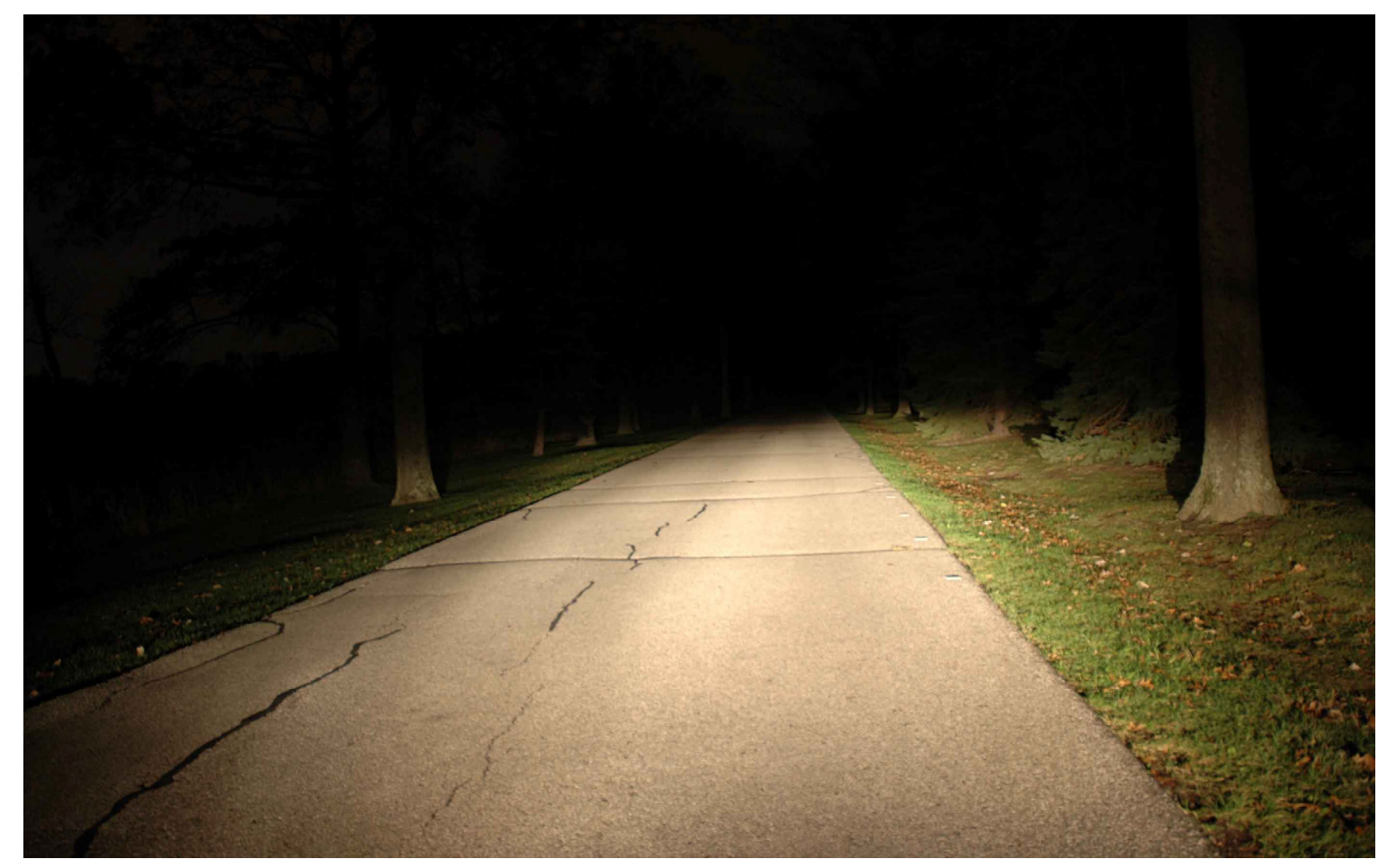

Figure 2. Night view from the participant's perspective.

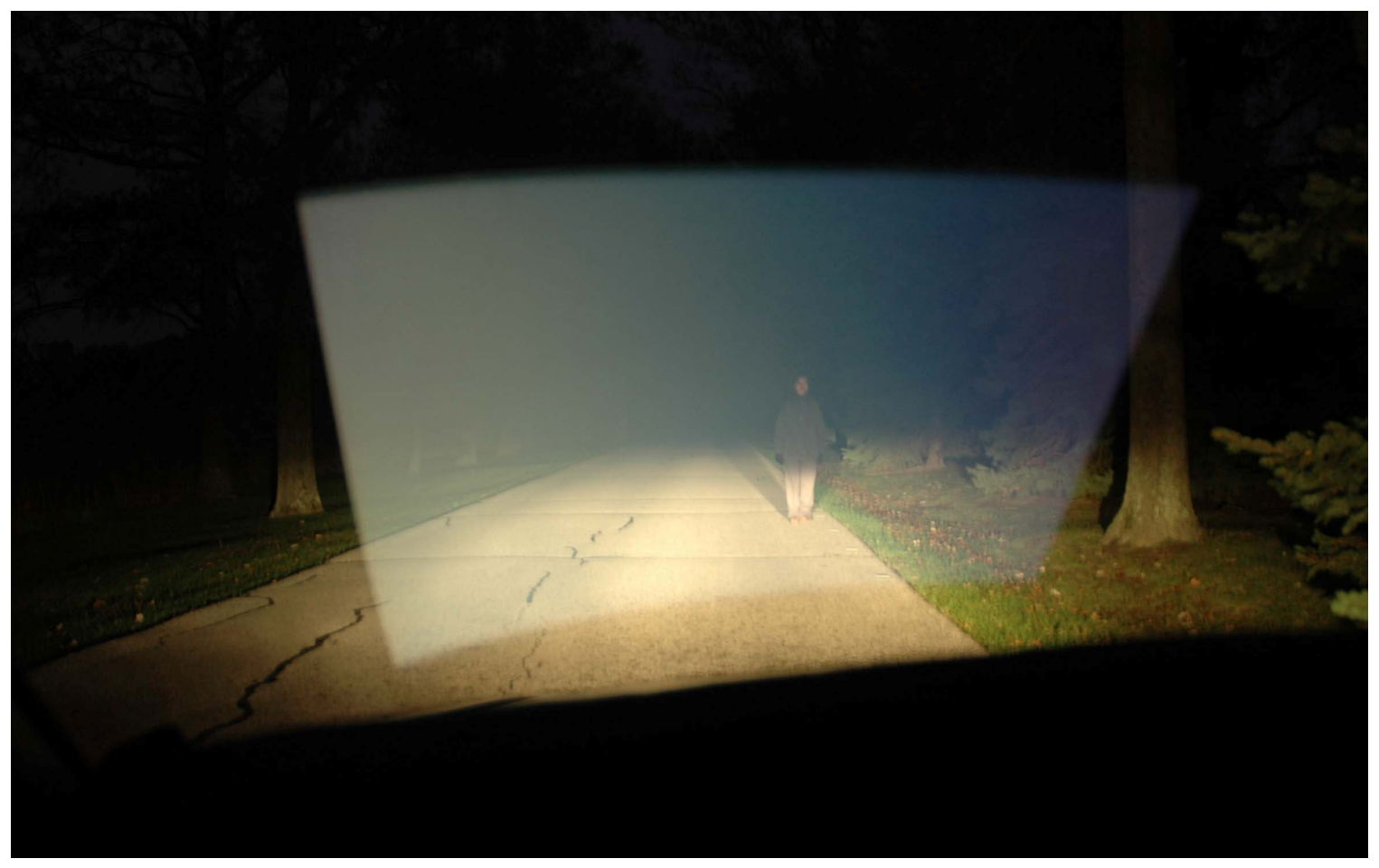

Figure 3. Windshield veiling luminance and pedestrian. 


\section{Experimental design and stimuli}

There were two parts to the experiment: pedestrian detection and brightness rating. Both parts consisted of repeated measures factorial designs (in which each participant experienced all combinations of the independent variables). The independent variables included the color and luminance of an image that was reflected on the vehicle's windshield. Three colors were used (white, blue, and red), and for each color, five levels of photopic luminance were presented: $0.5 \mathrm{~cd} / \mathrm{m}^{2}, 0.13 \mathrm{~cd} / \mathrm{m}^{2}, 0.0 .31 \mathrm{~cd} / \mathrm{m}^{2}$, $0.0078 \mathrm{~cd} / \mathrm{m}^{2}$, and $0.0 \mathrm{~cd} / \mathrm{m}^{2}$ (off). An additional independent variable was the location of the pedestrian on the road; the pedestrian was either on the right edge of the road or at the center of the road.

The dependent variables were the distance at which the participant could detect the pedestrian as she walked toward and away from the vehicle, and the participants' numerical ratings of brightness for each level of the reflected stimulus.

The order of stimuli for each participant was as follows: In the first part of the experiment (which was always the detection distance task) 30 trials were presented in two blocks, each of which consisted of all 15 combinations of luminance and color. In the first block, location (edge or center) was randomly selected for each trial. In the second block, the alternative location was selected for each combination of luminance and color. For example, if the pedestrian was on the edge of the road for the combination of red and $0.5 \mathrm{~cd} / \mathrm{m}^{2}$ in the first block, then the pedestrian would be at the center of the road for the combination of red and $0.5 \mathrm{~cd} / \mathrm{m}^{2}$ during the second block. The order of stimuli was randomized within each block of 15 trials.

In the second part of the experiment, the magnitude estimation task, only four levels of luminance were presented for each color (the "off" condition was excluded). Twenty-four trials were presented in two blocks, each of which consisted of all 12 combinations of luminance and color. The order of stimuli was randomized within each block of 12 trials.

The stimuli were photometrically equated in photopic luminance (i.e., using standard, daytime photometry). While there was some variation across the image of the LCD screen, the luminance of center of the image, as reflected in the windshield, for each of the three colors was set to 0.50 photopic candelas per square meter. The luminance 
and chromaticity data for the three colors are shown in Table 1. As shown in that table, the scotopic luminances and the resulting $\mathrm{S} / \mathrm{P}$ ratios of the three colors were different. The spectral power distributions of the three colors, as reflected in the windshield, are shown in Figure 4.

\section{Table 1}

Colorimetric and photometric values for the highest level of each color of the veiling stimuli

\begin{tabular}{|c|c|c|c|c|c|}
\hline \multirow{2}{*}{ Color } & \multicolumn{2}{|c|}{ CIE 1931 chromaticity } & \multicolumn{2}{c|}{ Luminance $\left(\mathrm{cd} / \mathrm{m}^{2}\right)$} & \multirow{2}{*}{ S/P ratio } \\
\cline { 2 - 5 } & $\mathrm{x}$ & $\mathrm{y}$ & Photopic & Scotopic & \\
\hline \hline White & 0.357 & 0.381 & 0.50 & 1.0 & 2.02 \\
\hline Blue & 0.163 & 0.125 & 0.50 & 4.0 & 7.94 \\
\hline Red & 0.564 & 0.364 & 0.50 & 0.35 & 0.69 \\
\hline
\end{tabular}

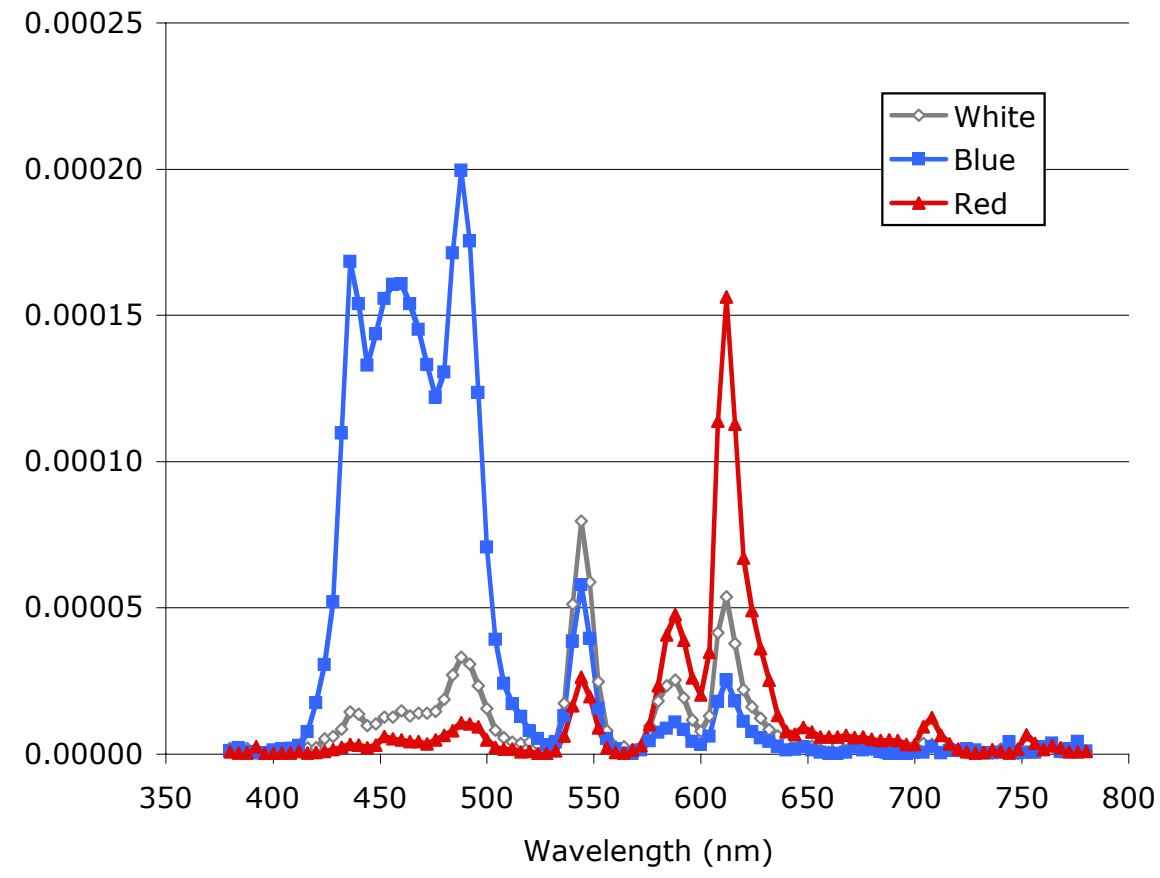

Figure 4. Spectra for the highest levels of the three colors of the veiling stimulus. 


\section{Procedure}

Each participant took part in one nighttime session, beginning after the end of civil twilight. After completing color vision and visual acuity screening tests, each participant arrived at the test location and sat in the driver's seat of the stationary test vehicle. An experimenter then read the instructions to the participant and answered any questions.

For the first part of the experiment, each trial began with the pedestrian standing at a distance well beyond the participant's ability to see her. The pedestrian then began walking at a moderate pace toward the vehicle, either on the right edge of the roadway or down the center. She continued walking until she heard the participant signal a detection by pressing a button on the two-way radio, at which point she noted her location (to the nearest half-meter), using a series of numbered markers that had been placed on the road at $2-\mathrm{m}$ intervals from 10 to $100 \mathrm{~m}$ in front of the vehicle. The markers were visible to the pedestrian, but not to the participant seated in the vehicle. The pedestrian then walked roughly ten meters closer, so that she would be clearly visible to the participant, turned around, and began to walk away at the same pace. Again, when she heard a radio signal from the participant, indicating this time that she was no longer visible, she noted her location. The experimenter inside the vehicle then changed the windshield condition, and the process was repeated for the next trial.

After all the pedestrian detection trials were complete, participants were given the instructions for the brightness rating task. They were shown the white stimulus at 0.13 $\mathrm{cd} / \mathrm{m}^{2}$, told that it corresponded to a brightness rating of 100 , and asked to use it as a reference for making their judgments. The experimenter then presented each level of luminance and color in a randomized order, asking for a rating of each stimulus. 


\section{RESULTS}

\section{Detection distance}

Detection distances were analyzed with a repeated measures ANOVA that included the independent variables age group (young, old), gender (male, female), color of the reflected image (white, blue, or red), luminance (4 discrete levels), and the lateral location of the pedestrian (right edge or center of the road).

\section{Luminance and color}

Figure 5 shows detection distance as a function of the color and luminance of the veiling reflected image on the windshield. Not surprisingly, detection distance increased as luminance decreased and was highest when luminance was zero (the "off" condition, represented by the horizontal line across all luminance values in Figure 5). The effect of luminance (tested for the four nonzero levels) was highly significant, $F(3,12)=39.7, p<$ .0001 . At very low levels, there appeared to be little if any difference from the zeroluminance condition.

There was little difference among colors; although detection distances tended to be slightly lower when the stimulus was blue, this effect did not reach significance, $F(2$, $8)=2.52, p=.14$.

\section{Age group and gender}

There were not significant effects of gender or age group on mean detection distance, although the effect of age approached significance, $F(1,4)=6.06, p=.070$. The nonsignificant tendency was in the direction that is usually observed, with the older group having, on average, shorter detection distances $(42.0 \mathrm{~m})$ than the younger group $(56.2 \mathrm{~m})$.

\section{Location of pedestrian}

There was very little difference in seeing distance for the pedestrian on the right edge of the road (50.0) compared to the center (49.5), and the difference was not statistically significant. Although the asymmetric light distribution of low-beam headlamps might be expected to lead to longer seeing distances further to the right, in this case the difference in lateral location may have been too small to cause a substantial difference in seeing distance. 


\section{Brightness ratings}

A repeated measures ANOVA was also used for brightness ratings. The independent variables were the same except that pedestrian lateral location did not apply. The logarithm (base 10) of each rating was used as the dependent measure. This is a standard method for reducing the subject-to-subject differences in scale that often occur in magnitude estimation tasks (Marks, 1974).

\section{Luminance and color}

Figure 6 shows log brightness rating as a function of the color and luminance of the stimulus. Not surprisingly, ratings of brightness generally increased as luminance increased. This effect was highly significant, $F(3,12)=49.4, p<.0001$. There was a distinct difference in ratings among the three colors. At any given luminance level, blue was rated as appearing brighter than red or white, and red was usually rated as the least bright. The overall effect of color was highly significant, $F(2,8)=100.2, p<.0001$.

Age group and gender

There was a significant effect of age group on brightness ratings, $F(1,4)=8.06, p$ $=.047$, with younger participants giving higher ratings (1.77) than older participants (1.53). The effect of gender was not significant. 


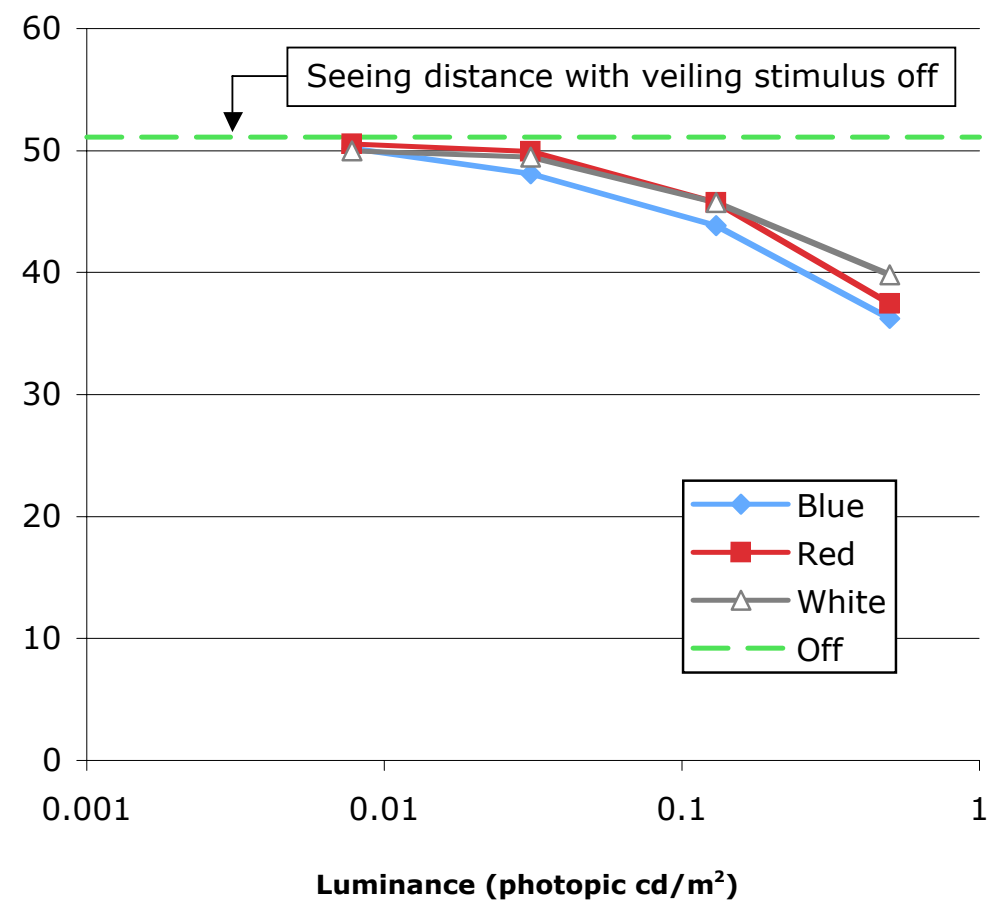

Figure 5. Mean detection distance by luminance and color of the veiling stimulus.

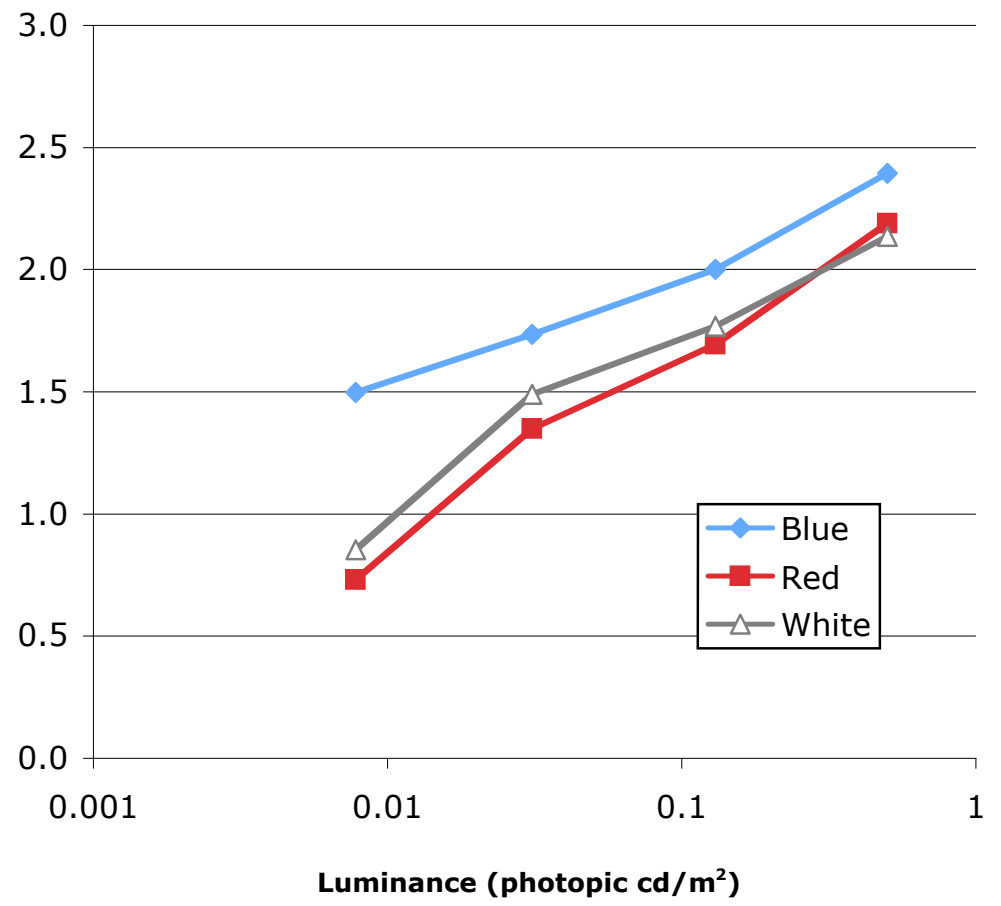

Figure 6. Log brightness rating for the veiling stimulus by luminance and color. 


\section{Modeling the effects of color}

The data in Figure 5 and Figure 6 can be used to derive estimates for the equivalent differences in luminance corresponding to the observed differences among the colors. Figure 7 and Figure 8 show regression models for data from the blue and red conditions. In the case of the detection distance data (Figure 7), we selected a quadratic polynomial model for distance regressed on the log of luminance. As can be seen in the figure, the fits were very good, with $r^{2}$ values exceeding 0.99 . For the brightness rating data (Figure 8), we used a linear model for log brightness rating regressed on $\log$ luminance. In this case, a quadratic component did not add significantly to the fit. Once again, the overall fits were good, with $r^{2}$ values of 0.98 and 0.99 for blue and red, respectively.

Using the regression models shown in Figure 7 and Figure 8, we calculated the equivalent luminance differences for the differences between the blue and red conditions. As can be seen in the figures, the slopes of the regression functions for the colors are different, so that the calculation of equivalent luminance differences depends on what level of the response variable (detection distance or brightness rating) is selected. Nevertheless, the relative effect of color for the two response variables is about the same for a broad range of those variables. For illustration, we selected the mean of both response variables, and the resulting calculations are represented graphically in Figure 7 and Figure 8.

For detection distance, the average over all participants and all conditions (except for when the veiling stimulus was off) was $45.6 \mathrm{~m}$. As shown in Figure 7, in terms of the regression function this distance corresponds to a luminance of $0.079 \mathrm{~cd} / \mathrm{m}^{2}$ for the blue stimuli, and a luminance of $0.13 \mathrm{~cd} / \mathrm{m}^{2}$ for the red stimuli. The resulting $\mathrm{red} / \mathrm{blue}$ ratio is 1.6. Therefore, at least at this range of detection distance, the data indicate that the effect of color on detection distance is such that a red veiling stimulus must be 1.6 times more luminous (in terms of photopic photometry) than a blue veiling stimulus.

For brightness ratings, the average log rating was 1.65 . This corresponds to a luminance of $0.019 \mathrm{~cd} / \mathrm{m}^{2}$ for the blue stimuli, and a luminance of $0.10 \mathrm{~cd} / \mathrm{m}^{2}$ for the red stimuli. The resulting red/blue ratio for brightness rating is 5.3, several times greater than the corresponding value of 1.6 that was estimated from the detection data. 
It is worth recalling that the effect of color was not statistically significant for detection distance, although it was for brightness rating. If there is, nevertheless, an effect of color on detection distance, the best estimates from these data indicate that it is considerably smaller than the effect of color on brightness ratings. 


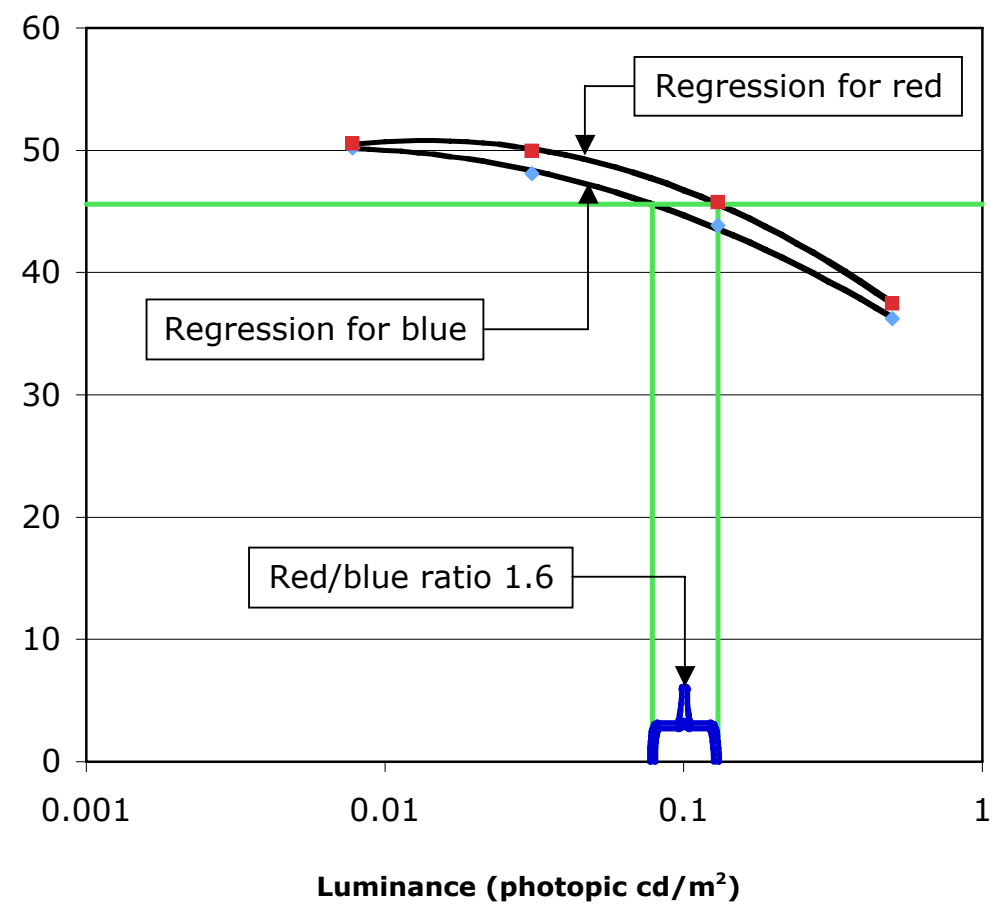

Figure 7. Model for a difference in luminance corresponding to the difference between blue and red for detection distance.

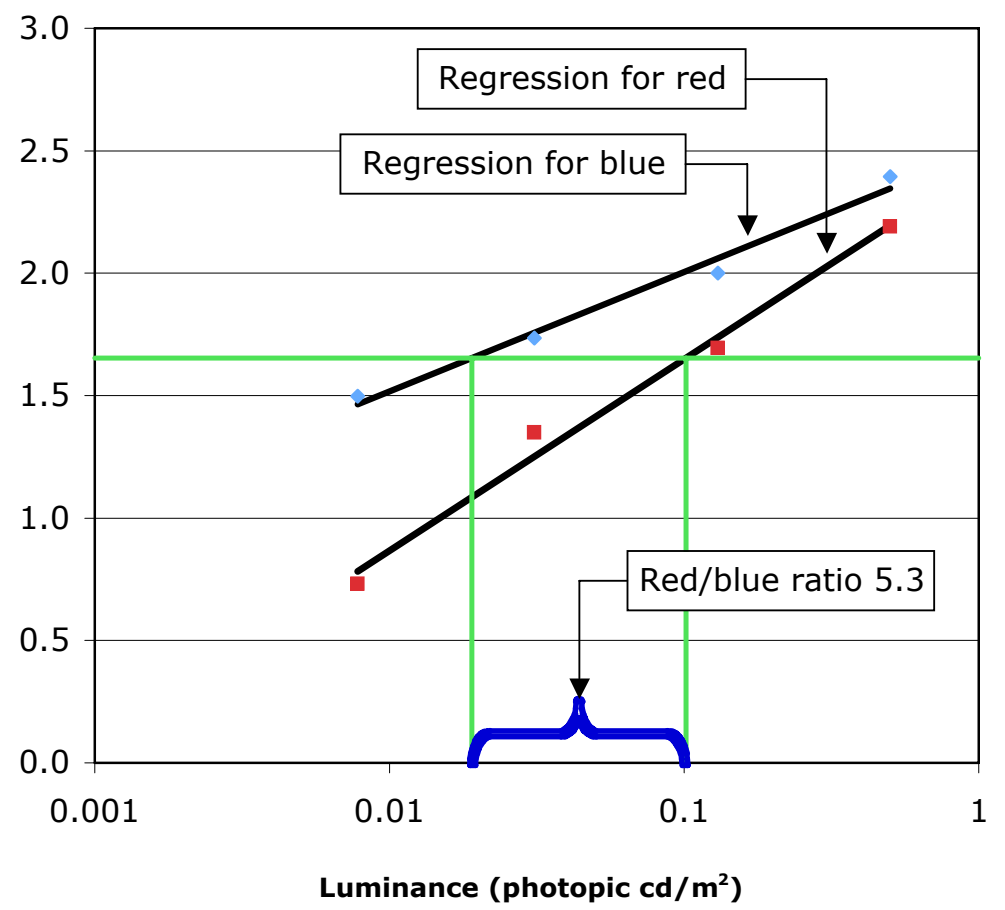

Figure 8. Model for a difference in luminance corresponding to the difference between blue and red for brightness ratings. 


\section{DISCUSSION AND CONCLUSIONS}

The results of the field study reported here have implications for the levels of veiling reflected light that can be expected to influence driver vision at night, and for the way those light levels should be measured when light sources are markedly colored. In both cases, however, the results should be considered preliminary, primarily because of the limited set of conditions that were examined. For this exploratory study, we chose to use the darkest conditions that would normally be of interest - headlamps on low beam on an otherwise dark road. That can be expected to maximize the effect of the veiling reflected light on performance of the pedestrian detection task. The lighting conditions in this experiment should therefore be considered a worst-case condition, although one that is reasonably common and important in the real world. The low level of light that participants were exposed to can also be expected to cause their visual adaptation to be at the low end of the range that prevails in normal night driving, which would in turn maximize the possible role of night vision, and scotopic photometry.

With regard to the levels of veiling light that may affect driver vision at night, the data in Figure 5 suggest that there is likely to be little effect at the lowest nonzero level that was used in this experiment, about $0.01 \mathrm{~cd} / \mathrm{m}^{2}$. By about $0.13 \mathrm{~cd} / \mathrm{m}^{2}$, the effect is measurable and possibly of practical importance for this very demanding task, detecting pedestrians with only low-beam headlamps. In order to provide definitive recommendations for light levels, the present data should be supplemented with additional data and analysis. In particular, there should be some consideration of individual differences in how drivers are affected by veiling light.

There was strong evidence in these results that, when light stimuli are matched in terms of photopic photometry, there is an effect of color on the rating of brightness but no clear evidence for an effect of color on pedestrian detection. This suggests that the form of photometry that is most appropriate may be different for different visual tasks. Specifically, photopic photometry seems to work well for predicting the effects of reflected veiling light on pedestrian detection, while it appears to systematically misrepresent the effects of color on the subjective experience of the brightness of the

same reflected veiling light. The effect of color on brightness is consistent with a possible heightened role of rod photoreceptors, as might be expected in the mesopic 
lighting conditions that participants experienced in the study. It is particularly interesting that there seems to be a divergence in how color affects the two specific tasks used in this study. This suggests that drivers could misjudge the ways that various colors of interior lighting affect their objective visual performance-for example, overestimating the effects of relatively blue, short-wavelength sources. A wider range of experimental conditions could be useful in better understanding such possible discrepancies.

This study was designed to quantify the effects of reflected veiling light on driver vision. It did not assess the possible effects of interior lighting on a driver's level of visual adaptation. Additional research should be done to investigate the effects of changes in visual adaptation that may result from drivers looking at bright displays that may be present in vehicles, such as navigation displays. In particular, it would be useful to investigate the effects of the displays on portable devices that may not be designed primarily for use in vehicles, and which therefore may have luminance levels that are relatively high and possibly not adjustable. 


\section{REFERENCES}

Grimm, M. (2003). Requirements for an ambient interior lighting system for motor vehicles. Doctoral Dissertation, Darmstadt University of Technology. Herbert Utz Verlag GmbH, München.

Imbeau, D. (1987). Effects of instrument panel luminance and hue on simulator driving performance and driver preferences. Doctoral Dissertation, Virginia Polytechnic Institute and State University, Blacksburg.

Kerst, J. \& Bos, T. (1988). Representative illumination levels of automobile instrument clusters (Technical Report No. UMTRI-88-33). Ann Arbor, MI: University of Michigan Transportation Research Institute.

Langolf, G. D., Mourant, G. D., \& Fisher, J. (1974). Specifications of control illumination limits (Report No. DOT/HS 801 260/ MVSS 101). Detroit, MI: Wayne State University, Department of Industrial Engineering and Operations Research.

Marks, L. E. (1974). Sensory processes: The new psychophysics. New York: Academic Press.

Navvab, M. (1991). Human factors and dynamic roadways and in-vehicle lighting conditions. Industry Applications Society Annual Meeting. Conference Record of the 1991 IEEE 28 vol. 2.

Olson, P. L. (1985). The effect of vehicle interior lighting systems on driver sight distance (Technical Report No. UMTRI-85-31). Ann Arbor, MI: University of Michigan Transportation Research Institute.

Serafin, C. \& Green, P. (1990). Driver preferences for instrument panel lighting levels (Technical Report No. UMTRI-90-5). Ann Arbor, MI: University of Michigan Transportation Research Institute. 